\title{
Article \\ Carriage of Multidrug Resistance Staphylococci in Shelter Dogs in Timisoara, Romania
}

\author{
Dégi János * (D), Herman Viorel D, Iancu Ionica, Pascu Corina, Florea Tiana * and Dascălu Roxana \\ Faculty of Veterinary Medicine, Banat's University of Agricultural Sciences and Veterinary Medicine Timișoara, \\ Calea Aradului 119, 300645 Timișoara, Romania; viorelherman@usab-tm.ro (H.V.); iancu.ionica@usab-tm.ro (I.I.); \\ corinapascu@usab-tm.ro (P.C.); roxana-dascalu@usab-tm.ro (D.R.) \\ * Correspondence: janosdegi@usab-tm.ro (D.J.); tijana.florea@usab-tm.ro (F.T.); Tel.: +40-767-089-041 (D.J.)
}

Citation: János, D.; Viorel, H.; Ionica, I.; Corina, P.; Tiana, F.; Roxana, D. Carriage of Multidrug Resistance Staphylococci in Shelter Dogs in Timisoara, Romania. Antibiotics 2021, 10, 801. https://doi.org/10.3390/ antibiotics 10070801

Academic Editors: John Barlow and Laura Selva Martínez

Received: 29 March 2021

Accepted: 26 June 2021

Published: 1 July 2021

Publisher's Note: MDPI stays neutral with regard to jurisdictional claims in published maps and institutional affiliations.

Copyright: (C) 2021 by the authors. Licensee MDPI, Basel, Switzerland. This article is an open access article distributed under the terms and conditions of the Creative Commons Attribution (CC BY) license (https:// creativecommons.org/licenses/by/ $4.0 /)$.
Abstract: The present study aimed to determine the prevalence of Staphylococcus species, which pose risks for public health, by evaluating skin samples collected from dogs in an animal shelter in Timisoara. Skin samples were taken from 78 dogs, which were either clinically healthy or suffering from dermatological conditions. Staphylococcus spp. was isolated and recognized based on conventional methods based on colony appearance, microscopic morphology, sugar fermentation, and coagulase activity. Following biochemical analysis, Staphylococcus isolates were subject to PCR tests to detect $s a-f$ and $s a-r$ genes to confirm the isolates to genus level. The typical colonies were identified to species level using biochemical methods, namely the VITEK ${ }^{\circledR} 2$ ID-GP64 identification card (bioMerieux, France). The phenotypic antimicrobial resistance profiling was performed using the VITEK ${ }^{\circledR} 2$ AST GP Gram-positive specific bacteria card (bioMerieux, France). Forty-three samples were confirmed as positive for Staphylococcus spp. Staphylococcus isolates were classified into the following categories: S. aureus, S. pseudintermedius, S. intermedius, S. epidermitis, S. haemolyticus, and S. hyicus. Eight $(18.60 \%, 8 / 43)$ out of all the samples harbored the mecA gene, highlighting the distribution among isolated staphylococcal species: Staphylococcus pseudintermedius $(4 / 43,9.30 \%)$, Staphylococcus intermedius $(1 / 43,2.32 \%)$ and Staphylococcus aureus $(3 / 43,9.30 \%)$, respectively. The phenomenon of resistance was present, to the following antimicrobial agents: erythromycin (38/43, $88.37 \%$ ), benzylpenicillin, kanamycin, and tetracycline with 37 strains (37/43, 86.04\%), gentamycin (30/43, 69.76\%), chloramphenicol $(29 / 43,67.44 \%)$, trimethoprim/sulfamethoxazole $(27 / 43,62.79 \%)$, ampicillin $(26 / 43,60,46 \%)$, rifampicin $(25 / 43,58,13 \%)$, imipenem $(14 / 43,32,55 \%)$, nitrofurantoin $(11 / 43,25.58 \%)$, oxacillin $(8 / 43,18.60 \%)$, vancomycin $(4 / 43,9.30 \%)$ and clindamycin $(3 / 43,6.97 \%)$, respectively. The presence of multidrug-resistant zoonotic staphylococci in clinically healthy dogs and dogs with skin lesions is an animal health and human health concern.

Keywords: staphylococci; dogs; resistance; public health

\section{Introduction}

Bacteria of the genus Staphylococcus are Gram-positive, facultative anaerobic cocci and are members of normal cutaneous and mucosal microbiota of mammals and birds. Various Staphylococcus species will colonize most animals with a certain site-predisposition [1,2].

Along with the outset of antimicrobial drug use in the practice of modern human and veterinary medicine, staphylococci have undergone evolutionary processes in response to the presence of antimicrobial drugs in biological systems. This evolution implied a novel development or acquisition of antimicrobial drug resistance mechanisms, in addition to the amplification and proliferation of clinically important strains of pathogenic staphylococci affecting human and animal populations.

Some degree of antimicrobial resistance has been documented within all Staphylococcus species that infect humans and domestic animals.

Methicillin-resistant Staphylococcus aureus (S. aureus) (MRSA) is a major healthcareassociated pathogen worldwide and has increased in incidence dramatically over the 
last decade [1,2]. Companion animals have been implicated more frequently as potential reservoirs of MRSA than other livestock [3,4]. A $0-4 \%$ prevalence rate of MRSA in dogs has been reported [5-7]. Other reports demonstrated MRSA at a higher prevalence ( 9\%) in pets and veterinary staff $[8,9]$. The nasal and skin carriage of MRSA plays a crucial role in the epidemiology and pathogenesis of community-associated infection.

In Romania, the antibiotic susceptibility testing of bacterial strains isolated from dogs (including stray dogs) was focused on the Staphylococcus genus. It was carried out mainly in veterinary teaching units during the past twenty years $[4,5]$. In addition, a recent review strengthens the imperative need for an integrated surveillance system in the One Health context of antimicrobial resistance profiles of zoonotic bacteria including Staphylococcus spp. [10]. Hence, the present study was designed to investigate the incidence of the staphylococcal microbiota in shelter dogs that were either healthy or presenting a skin condition and provide new information on their antimicrobial resistance profile (AMR).

\section{Results}

A total of 78 skin samples were investigated for the presence of Staphylococcus spp., between June and October 2019, and $43(55.12 \%)$ of these samples were found to be positive for Staphylococcus spp.

Species identification was performed based on colony and microscopic morphology, sugar fermentation, pigment production in blood agar, and coagulase activities [6].

All the isolates $(n=43)$ were confirmed as Staphylococcus spp. by PCR amplification of the inv $A$ genes, which generated amplicons of $284 \mathrm{bp}$. A total of 43 samples were confirmed positive for Staphylococcus spp. by conventional and molecular methods. However, we were unable to amplify DNA of interest extracted from 19 skin sample isolates, which, following primary processing (inoculated on culture media: Columbia agar with $5 \%$ Sheep Blood, MacConkey agar and Chapman Mannitol Salt agar, respectively) proved positive for other bacterial species. Similarly, we could not use 16 other samples that tested negative.

Overall, $43(43 / 78,55.12 \%)$ isolates of Staphylococcus spp. were identified (Table 1).

Table 1. Distribution of positive skin samples for Staphylococcus spp., according to gender.

\begin{tabular}{cc}
\hline Gender & No. of Positive Samples/No. of Investigated (\%) \\
\hline Female & $27 / 49(55.10)$ \\
\hline Male & $16 / 29(55.17)$ \\
\hline Total & $43 / 78(55.12)$ \\
\hline
\end{tabular}

The result obtained using the Vitek $2^{\circledR}$ ID-GP card may be categorized into one of several confidence levels (excellent, very good, good, acceptable, good, low, unidentified, and error), specified in Table 2.

S. pseudintermedius, S. intermedius, and S. aureus, respectively, are the main species isolated from the skin of shelter dogs, with usefulness in monitoring the risk factors implied by staphylococcal infections. The Staphylococcus pseudintermedius was detected in $48.83 \%$ (21/43) of samples, Staphylococcus intermedius in $27.90 \%(12 / 43)$, Staphylococcus aureus in $11.62 \%$ (5/43), Staphylococcus epidermidis in 9.01\% (3/43), one Staphylococcus hyicus isolate $(2.32 \%, 1 / 43)$ and one isolate was Staphylococcus haemolyticus $(2.32,1 / 43)$ (Table 2).

PCR genotyping confirmed that the isolates were positive for $S$. pseudintermedius (21 isolates), S. intermedius (12 isolates), S. aureus (5 isolates), S. epidermidis (3 isolates), S. hyicus and S. haemolyticus (each with one isolate).

Detection of the mecA gene represents the standard procedure for determining resistance to methicillin. From the total number of isolates, $8(18.60 \%, 8 / 43)$ harbored the mecA gene, highlighting the distribution of isolated staphylococcal species: Staphylococcus pseudintermedius $(4 / 43,9.30 \%)$, Staphylococcus intermedius $(1 / 43,2.32 \%)$ and Staphylococcus aureus $(3 / 43,9.30 \%)$. 
Table 2. Result of Staphylococcus spp. strains testing with Vitek $2^{\circledR}$ ID-GP identification card (bioMérieux. Marcy l'Etoile, France).

\begin{tabular}{|c|c|c|c|c|c|c|c|c|}
\hline \multirow{2}{*}{ Identified Strains } & \multicolumn{8}{|c|}{ No. $(\%)$ of Strains Identified According to the Vitek $2^{\circledR}$ ID-GP Indicators } \\
\hline & $\mathbf{N}(\%)$ & Excellent & Verry Good & Acceptable & Good & Low & Unidentified & Error \\
\hline $\begin{array}{c}\text { Staphylococcus } \\
\text { pseudintermedius }\end{array}$ & $21(48.83 \%)$ & 18 & 3 & - & - & - & - & - \\
\hline $\begin{array}{c}\text { Staphylococcus } \\
\text { intermedius }\end{array}$ & $12(27.90 \%)$ & 8 & 4 & & & & & \\
\hline Staphylococcus aureus & $5(11.62 \%)$ & 3 & 2 & & & & & \\
\hline $\begin{array}{l}\text { Staphylococcus } \\
\text { epidermidis }\end{array}$ & $3(9.01 \%)$ & 3 & - & & & & & \\
\hline $\begin{array}{c}\text { Staphylococcus } \\
\text { haemolyticus }\end{array}$ & $1(2.32 \%)$ & 1 & - & & & & & \\
\hline Staphylococcus hyicus & $1(2.32 \%)$ & 1 & & & & & & \\
\hline Total & $43(100 \%)$ & 34 & 9 & - & - & - & - & - \\
\hline
\end{tabular}

The most common lesions, which also served as collection sites for Staphylococcus spp. strains were as follows: erythema, 25.58\% (11/43 strains); pustules, $13.05 \%$ (6/43 strains); hyperkeratosis lesions $6.97 \%$ (3/43 strains) and alopecia 4.65\% (2/43 strains), respectively (Table 3). Forty-six stray dogs, which had their skin sampled, showed skin lesions, while thirty-two of them did not have associated skin diseases.

Table 3. Distribution of skin samples that were positive for Staphylococcus spp., according to clinical aspects.

\begin{tabular}{|c|c|c|c|c|c|c|c|c|}
\hline \multirow{3}{*}{ Clinical Result } & \multicolumn{7}{|c|}{ Samples from Stray Dogs with Skin Lesions } & \multirow{2}{*}{$\begin{array}{l}\text { Samples from Stray Dogs } \\
\text { without Skin Lesions } \\
\text { Without Clinical Signs }\end{array}$} \\
\hline & Erythema & Peeling & Alopecia & Pruritus & Scabs & Pustules & Hyperkeratosis & \\
\hline & $21(26.92 \%)$ & $2(2.56 \%)$ & $9(11.53 \%)$ & $3(3.84 \%)$ & $2(2.56 \%)$ & $6(7.69 \%)$ & $3(3.84 \%)$ & $32(41.02 \%)$ \\
\hline \multirow{2}{*}{$\begin{array}{l}\text { Total collected } \\
\text { samples }\end{array}$} & \multicolumn{7}{|c|}{46 (58.97\%) } & $32(41.02 \%)$ \\
\hline & \multicolumn{8}{|c|}{$78(100 \%)$} \\
\hline $\begin{array}{c}\text { Positive } \\
\text { Staphylococcus spp. } \\
\text { samples }\end{array}$ & $11(25.58 \%)$ & $1(2.32 \%)$ & $2(4.65 \%)$ & $1(2.32 \%)$ & $1(2.32 \%)$ & $6(13.05 \%)$ & $3(6.97 \%)$ & $18(41.87 \%)$ \\
\hline \multirow{2}{*}{ Total samples } & \multicolumn{7}{|c|}{$25(58.13 \%)$} & $18(41.87 \%)$ \\
\hline & \multicolumn{8}{|c|}{$43(100 \%)$} \\
\hline
\end{tabular}

All of the 43 studied Staphylococcus isolates were resistant to at least three antimicrobial agents. All identified strains were susceptible to ampicillin/sulbactam, enrofloxacin, marbofloxacin, and mupirocin. The phenomenon of resistance was manifested against several antibiotics such as: erythromycin $(38 / 43,88.37 \%)$, benzylpenicillin, kanamycin, and tetracycline in the case of 37 strains $(37 / 43,86.04 \%)$, gentamycin $(30 / 43,69.76 \%)$, chloramphenicol $(29 / 43,67.44 \%)$, trimethoprim/sulfamethoxazole $(27 / 43,62.79 \%)$, ampicillin $(26 / 43,60.46 \%)$, rifampicin $(25 / 43,58.13 \%)$, imipenem $(14 / 43,32.55 \%)$, nitrofurantoin $(11 / 43,25.58 \%)$, oxacillin $(8 / 43,18.60 \%)$, vancomycin $(4 / 43,9.30 \%)$, clindamycin and fusidic acid (3/43,6.97\%), respectively (Table 4).

Statistical analysis was performed using a Chi-square $(\chi 2)$ test in SPSS version 21.0 for Windows (SPSS Inc., Chicago, IL, USA) in order to evaluate the probability that $S$. pseudintermedius and $S$. intermedius demonstrate resistance towards the tested antimicrobials. The differences with $p<0.05$ were considered statistically significant.

Following genetic analysis, it was revealed that all eight isolates, phenotypically demonstrating oxacillin resistance, harbored the mec $A$ gene.

Vancomycin is the drug of choice when it comes to treating invasive MRSA infections [11]. Out of the eight isolates of MRSA included in the study, none have developed 
resistance to vancomycin (VRSA) according to the revised CLSI guidelines. The MIC of vancomycin-resistant strains ranged from $0.5 \mu \mathrm{g} / \mathrm{mL}$ to $4 \mu \mathrm{g} / \mathrm{mL}$.

Table 4. Patterns of resistance in Staphylococcus spp. $(n=43)$, obtained from stray dogs with skin lesions, exhibiting resistance for more than three antimicrobials.

\begin{tabular}{|c|c|c|c|c|}
\hline No. & Staphylococcus spp. & No. of Isolates & Resistance to Antimicrobial Profile & $\begin{array}{l}\text { No. of Antimicrobials } \\
\text { Resistant }\end{array}$ \\
\hline 1. & $\begin{array}{l}\text { Staphylococcus } \\
\text { pseudintermedius }\end{array}$ & 6 & $\begin{array}{l}\text { AM, PCG, CHL, ERY, K, GM, RIF * TE, } \\
\text { STX }\end{array}$ & 9 \\
\hline 2. & $\begin{array}{l}\text { Staphylococcus } \\
\text { pseudintermedius }\end{array}$ & 4 & $\begin{array}{c}\text { AM, PCG, CHL, ERY, CLI, K, GM, OXA, } \\
\text { TE, STX }\end{array}$ & 10 \\
\hline 3. & $\begin{array}{l}\text { Staphylococcus } \\
\text { pseudintermedius }\end{array}$ & 3 & $\begin{array}{c}\text { AM, PCG, CHL, ERY, K, GM, TE, VAN * } \\
\text { FT, STX }\end{array}$ & 10 \\
\hline 4. & $\begin{array}{l}\text { Staphylococcus } \\
\text { pseudintermedius }\end{array}$ & 3 & AM, PCG, IPM, ERY, K, RIF *, TE, FUS, & 8 \\
\hline 5. & $\begin{array}{l}\text { Staphylococcus } \\
\text { pseudintermedius }\end{array}$ & 3 & PCG, CHL, ERY, K, RIF * TE, IPM * & 7 \\
\hline 6. & $\begin{array}{l}\text { Staphylococcus } \\
\text { pseudintermedius }\end{array}$ & 2 & PCG, CHL, ERY, K, GM, RIF * , TE, FT & 8 \\
\hline 7. & $\begin{array}{l}\text { Staphylococcus } \\
\text { intermedius }\end{array}$ & 4 & AM, PCG, CHL, ERY, K, GM, TE, STX & 8 \\
\hline 8. & $\begin{array}{l}\text { Staphylococcus } \\
\text { intermedius }\end{array}$ & 4 & PCG, ERY, K, GM, RIF * TE, STX & 7 \\
\hline 9. & $\begin{array}{l}\text { Staphylococcus } \\
\text { intermedius }\end{array}$ & 3 & $\mathrm{AM}, \mathrm{IPM}^{*}, \mathrm{GM}, \mathrm{RIF}, \mathrm{FT}, \mathrm{VAN} *$ & 6 \\
\hline 10. & $\begin{array}{l}\text { Staphylococcus } \\
\text { intermedius }\end{array}$ & 1 & PCG, CHL, CLI, ERY, K, OXA, STX & 7 \\
\hline 11. & Staphylococcus aureus & 3 & PCG, CHL, ERY, K, OXA, GM, TE, STX & 8 \\
\hline 12. & Staphylococcus aureus & 1 & AM, CHL, K, TE, STX, VAN * & 6 \\
\hline 13. & Staphylococcus aureus & 1 & PCG, CLI, GM, IPM * FT, RIF * & 6 \\
\hline 14. & $\begin{array}{l}\text { Staphylococcus } \\
\text { epidermidis }\end{array}$ & 2 & PCG, CHL, IPM *, ERY, K, RIF *, TE & 7 \\
\hline 15. & $\begin{array}{l}\text { Staphylococcus } \\
\text { epidermidis }\end{array}$ & 1 & AM, PCG, FT, ERY, K, IPM *, CLI, TE & 8 \\
\hline 16. & $\begin{array}{l}\text { Staphylococcus } \\
\text { haemolyticus }\end{array}$ & 1 & AM, PCG, IPM * ERY, FT, STX & 6 \\
\hline 17. & Staphylococcus hyicus & 1 & PCG, ERY, K, RIF *, TE & 5 \\
\hline
\end{tabular}

Legend: Ampicillin (AM), Ampicillin/Sulbactam (SAM), Benzylpenicillin (PCG), Clindamycin (CLI), Chloramphenicol (CHL), Erythromycin (ERY), Enrofloxacin (ENR), Fusidic acid (FUS), Gentamicin (GM), Imipenem (IPM), Kanamycin (K), marbofloxacin (MBX), Mupirocin (MUP), nitrofurantoin (FT), Oxacillin (OXA), Rifampicin (RIF), Tetracycline (TE), Vancomycin (VAN) and Trimethoprim/Sulfamethoxazole (SXT). * the first-line antimicrobial agents used in the treatment of MRSA.

\section{Discussion}

The nature of animal shelters that keep many animals in a confined space increases bacterial transmission. Proper preventive care remains a challenge to the resident animals and the people working and visiting there [12]. Another study conducted by GonzalesDominguez et al. [8] describes that $100 \%$ of dogs with superficial skin infections tested positive for Staphylococcus species, suggesting a high incidence of this genus in dogs dermatologic pathologies.

The recorded Staphylococcus isolates in the present study expressed resistance towards methicillin and other antimicrobials (e.g., gentamicin, erythromycin, and tetracycline) commonly used to treat skin infections. In conclusion, MRSA can be considered a frequently 
found microorganism in shelter animals, with widespread resistance to the currently used antibiotics. [13].

Staphylococcus spp., considered a ubiquitous bacterium that covers all ecological niches, might be accompanied by AMR characteristics. The complex relationships between bacterial species from different "environments" facilitate this genetic flow, extending AMR between humans, animals, and the environment, resulting in a general public health issue [14]. Staphylococcus methicillin resistance is one of these significant problems of society. An animal shelter may act as a reservoir of MRSA, considering some particular setting, with a high colonization rate, which can reach $7.8 \%$ in shelter dogs (reviewed by [15-17]). Accurate and timely determination of methicillin resistance is of crucial importance in the prognosis of $S$. aureus infections [18,19]. These strains have spread in the community (MRSA-CA-MRSA associated with the community) and have been incriminated in cases of severe infection in healthy individuals [20-23]. The rate of colonization with this bacterium in dogs varies significantly; however, about $10 \%$ of dogs can act as carriers of S. aureus [11]. The growing concern about the spread of MRSA in communities has led to the establishment of particular recommendations for surveillance, including research into the rate of colonization in healthy dogs (including stray dogs present in public areas, which may later be adopted).

Exposure to shelter dogs or the living environment of these dogs can be considered a risk factor for colonization with CA-MRSA strains; thus, it is essential to identify community and environmental reservoirs and sources. In this regard, it is imperative to precisely determine the phenotype of resistance and the mechanisms underlying resistance, which are essential in therapy and public health. The most widely used method, considered a gold standard in identifying MRSA strains, is to identify the mecA gene.

The most important mechanism of resistance in staphylococci is resistance to methicillin, which, clinically speaking, implies resistance to all $\beta$-lactam antibiotics, often accompanied by resistance to many other groups of antimicrobial agents. It is estimated that $30 \%$ of the world's population could be colonized with S. aureus [11]. Rajwin Raja Kanagarajah et al. [12], in a study on antibiotic profiling of methicillin resistant Staphylococcus aureus (MRSA) isolates in stray canines and felines from India, isolated 283 strains of staphylococci, of which $33(11.66 \%$ ) were MRSA, using CromMRSA agar medium (Chromagar, Oxoid, United Kingdom). Canine MRSA isolates exhibited resistance, in decreasing order, to methicillin $(100 \%)$, ceftazidime $(81.82 \%)$, enrofloxacin $(78.79 \%)$, oxacillin $(60.61 \%)$, and vancomycin $(0 \%)$. Over the years, frequent and random use of vancomycin may bear the responsibility for the emergence of vancomycin resistance among the S. aureus isolates [11].

Staphylococcus pseudintermedius is an opportunistic pathogen that has been identified as an infectious agent or colonizer, mainly in dogs. S. pseudintermedius has also been detected in humans, more specifically in people that are in close contact with dogs [7]. Multidrug methicillin-resistant Staphylococcus pseudintermedius (MRSP) detection has rapidly increased among microbial specimens from pets across Europe. (reviewed by [24]). S. pseudintermedius carriage is frequently more significant than $80 \%$ in some healthy dog populations. It is also an opportunistic pathogen that causes severe and necrotizing infections and is commonly found in the skin, ears, bones, and post-surgical abscesses [25]. Considered as a risk for humans, there is a possibility for it to have been misidentified as S. aureus in human infections [25]. The dogs may be colonized or infected with MRSP on healthy skin, fur, and mucosae even after the infections have healed spreading MRSP to their environment, other species, and humans.

It also serves as a reservoir of re-infection with MRSP. Although MRSA transmission in humans is well understood, little is known about MRSP carriage and it's spread in dogs (reviewed by $[16,26])$. In the recent literature, S. pseudintermedius is one of the important pathogens of zoonotic origin that causes wound and skin infections in humans. According to the literature, up to $90 \%$ of healthy dogs may be colonized with S. pseudintermedius [27]. Antimicrobial resistance is being caused by the unjustified use of antimicrobials in com- 
panion animals. S. pseudintermedius is another element in the same chain of evolving drug resistance. It is multidrug-resistant, capable of transmitting from animals to humans, and possesses many S. aureus virulence factors [22]. Although data on drug resistance and pathogenesis of S. pseudintermedius are not sufficient, it is imperative to identify the pathogen correctly. Resistance to beta-lactam antibiotics (including methicillin) is a significant concern. Methicillin resistance is a significant concern in developed countries when antibiotic usage is unregulated. Multidrug tolerant isolates from clinical specimens have been published in European studies [28-30].

Resistance to erythromycin, clindamycin, tetracycline, trimethoprim-sulfamethoxazole, and ciprofloxacin was identified among S. pseudintermedius strains by Lozano et al. [7] as well. The matter of drug resistance among strains of Staphylococcus is an increasingly serious concern. However, the susceptibility of Staphylococcus to antimicrobial drugs varies among countries and regions [8-10]. The recently introduced term 'One Health' states that only 'One' health is shared by humans, animals, and the ecosystem, explicitly insinuating that anything that affects one will ultimately affect all three components [31-33]. Currently, the One Health concept is advocated for antimicrobial resistance [31,32]. Therefore, One Health-based approach to fight antimicrobial resistance has been promoted as a global challenge [33]. To support the application of the One Health-based approach to combat antimicrobial resistance, research on the human-animal-environmental interface is essential [33]. There at present are no shelter-specific MRSA and MRSP control guiding principles but existing Guidelines for Standards of Care in Animal Shelters, adopted by The Associations of Shelters Veterinarians. However, general infection control strategies should always be used to prevent infectious agent spread among shelter animals and decrease the probability of environmental contamination. Such should aid in the control of MRSA and MRSP if the bacteria are present in the animals or environment and will help to protect both animal and human populations in the shelter environment [34].

The detection of MRSA in a $9.30 \%$ percentage in our study indicates a high prevalence of MRSA colonization rate in the shelter dogs population tested, compared to others study, findings of $1-2 \%$ MRSA prevalence in hospitalized dogs [35], $0-0.4 \%$ in healthy animals [36], respectively $7.8 \%$ in shelter dogs (reviewed by [15-17]). MRSP prevalence was between $0.5-16.7 \%$ in healthy dogs [37]. The MRSP prevalence in the shelter dogs of our study $(9.30 \%)$ is within the range of most studies. Animals from shelters may be more exposed to the risk of colonization or even of developing infections caused by various agents (e.g., zoonotic Staphylococcus spp.). Several reasons may stand behind this exposure: high density of individuals, the possibility of nosocomial transmission from shelter staff members or volunteers, suboptimal cleaning and disinfecting protocols, and the unidentified carrier status of high numbers of animals, or a stressful environment [38].

\section{Conclusions}

This study shows that sheltered animals are likely an unusual source of infections for shelter staff or potential adopters. Methicillin-resistant staphylococci are a substantial public health risk. Animals in a shelter may, in the end, end up in the homes of a wide range of possible adopters: homes with young children, healthy humans, and immunocompromised, respectively. As well, other species of coagulase-positive staphylococci have been isolated, such as S. intermedius and S. pseudintermedius, considered zoonotic, producing various infections in both dogs and humans.

The data from this study reveal that resistance to beta-lactams and other classes of antibiotics are omnipresent in the medically significant species of pathogenic staphylococci that colonize shelter dogs. This situation poses a high risk of transmission of MDR strains or mobile elements encoding resistance in humans, being in close contact with those animals and their microbiota. The results highlight the need for reliable implementation of the One Health concept; considering all the interconnections between human populations and shelter dogs, these pathogenic staphylococcal species and their resistance mechanisms can be transmitted. 
The study results are confined to the individual, single shelter, and future research is essential to establish whether rates similar across shelters, regions, and other source animals, such as pet shops, breeders, were similar. We hope that this study will increase public health-related responsiveness regarding biosecurity measures and manure or animal shelter waste management.

\section{Materials and Methods}

\subsection{Sample Collection}

The dogs that made the subject of this study were in the custody of two of the community dog collection centers, under the management of Timisoara City Hall, in collaboration with the University Veterinary Clinics of the Timisoara Faculty of the Timisoara Faculty of Veterinary Medicine.

All dogs enrolled in the study were taken from the streets of Timisoara and housed in two specialized centers for stray dogs.

The samples were meant to serve as material for evaluating the possible public health risk posed by these animals as well as for establishing the rate of zoonotic staphylococcal carriage among the population of stray dogs. All methods were performed in accordance with the relevant guidelines and regulations. A dog with skin lesions was defined as an animal currently presenting a skin condition: erythema, scaling, alopecia, pruritus, crusts, pustules, and hyperkeratosis, while dogs without skin lesions were defined as healthy. A total of 78 skin samples were collected from shelter dogs between June and October 2019, and screened in order to obtain an estimative prevalence of zoonotic drug-resistant Staphylococcus spp., in an urban area of Timisoara City (DMS Coordinate: $45^{\circ} 45^{\prime} 13.39^{\prime \prime}$ N, $21^{\circ} 13^{\prime} 32.56^{\prime \prime}$ E), western Romania. The samples from animals that appeared clinically healthy (stray dogs without skin lesions) were collected with the help of students that were enrolled in the practice program at the University Veterinary Clinic from the Faculty of Veterinary Medicine, Timisoara. The sample-collection protocol was chosen in agreement with regulations imposed by the Romanian Veterinary College (protocol numbers 34/1.12.2012) and according to current practice at the University Veterinary Clinics of the Faculty of Veterinary Medicine from Timisoara.

A standard procedure was established to recruit both animals with and without skin lesions for this study.

The skin samples were obtained from dogs with skin lesions, following specialty evaluation, performed on-site at the dog shelter. The students were volunteers enrolled in the study after receiving proper training on collecting samples in compliance with all biosecurity measures [37].

\subsection{Bacterial Isolation}

Staphylococcus spp. was isolated using conventional methods [39], as mentioned in the protocols recommended by the samples, collected using the eSwab ${ }^{\mathrm{TM}}$ (Copan, Italy) transport systems, were subsequently stored in cooling containers and transported, according to the biological sample collection and transport guidelines, to the research laboratory of transmissible diseases in pets (B.6.d), where the samples were processed in the shortest possible time (max. $3 \mathrm{~h}$ post-collection).

The samples were processed in the Bacterial Diseases diagnostic laboratory (B.6.a), within the Department of Infectious Diseases and Preventive Medicine, of the Faculty of Veterinary Medicine Timisoara.

The samples were inoculated onto BD Columbia Agar plates, with 5\% Sheep Blood (Becton Dickinson $\mathrm{GmbH}$, Heidelberg, Germany), and incubated at $37^{\circ} \mathrm{C}$ for $24 \mathrm{~h}$, under aerobic conditions $[39,40]$ The identification of staphylococci in primary culture, was based on colony morphology, appearance, type of hemolysis, and Gram staining.

The specific colonies that resulted from Columbia agar with 5\% Sheep Blood were also inoculated on MacConkey agar (Thermo Fisher Scientific, UK) using a bacteriological loop and incubated at $35^{\circ} \mathrm{C}$, in an aerobic atmosphere, for $24 \mathrm{~h}$. In addition, the production 
of "free coagulase" and the presence of the "clumping factor" was also determined using rapid slide agglutination tests such as Bactident Coagulase (Merck, Darmstadt, Germany) and Staphytect Plus (Oxoid, Ltd., Basingstoke, UK), respectively.

Following this preliminary stage, the colonies presenting phenotypical characteristics specific for Staphylococcus spp. were transferred on Chapman (mannitol salt) agar medium (Thermo Fisher Scientific, Basingstoke, UK) to facilitate the identification of pathogenic Staphylococcus strains based on their biochemical characteristics (mannitol fermentation) and for their purification. The plates were incubated at $37^{\circ} \mathrm{C}$, in an aerobic atmosphere, for $24 \mathrm{~h}$.

In order to identify Staphylococcus species, we inoculated Vitek $2^{\circledR}$ ID-GP identification cards (bioMérieux. Marcy l'Etoile, France) with Staphylococcus strains, according to the manufacturer's guidelines and the results were analyzed and interpreted using the VT2Software program, version R02. 03.. The Vitek $2^{\circledR}$ ID-GP card is a 64-well card designed for the automated identification of most veterinary, clinically significant Gram-positive bacteria [41].

All characterized isolates have shown very good ( $\%$ ID $\geq 99.0$, $\mathrm{T}$ index $\geq 0.5$ ) confidence levels.

\subsection{Molecular Analyses}

DNA was extracted from the biochemically identified isolates as Staphylococcus spp., using the PureLink ${ }^{\mathrm{TM}}$ Genomic DNA Mini Kit (Thermo Fisher Scientific, UK).

DNA was extracted from samples cultivated in Remel ${ }^{\mathrm{TM}}$ BHI Broth (Brain Hearth Infusion broth-Thermo Fisher Scientific, Basingstoke, UK) by inoculating presumed Staphylococcus spp. colonies, after incubation at $37^{\circ} \mathrm{C}$ under conditions of aerobiosis, for $24 \mathrm{~h}[42]$.

\section{Extraction of Template DNA}

One milliliter of bacteria grown in 10 milliliters of Remel ${ }^{\mathrm{TM}} \mathrm{BHI}$ Broth (Brain Hearth Infusion broth-Thermo Fisher Scientific, UK), at $37^{\circ} \mathrm{C}$ in an aerobic atmosphere for $24 \mathrm{~h}$, was dispensed aseptically in an Eppendorf tube. Bacterial genomic DNA was extracted using the Pure Link ${ }^{\mathrm{TM}}$ Genomic Lysis/Binding Buffer (Thermo Fisher Scientific, UK) boiling method, with a freshly-prepared proteinase K solution $(10 \mathrm{mg} / \mathrm{mL})$ as described previously by Rantakokko-Jalava and Jalava [31]. The DNA quantity and quality were determined using a Nano Drop ND-1000 spectrophotometer (Nano Drop ${ }^{\circledR}$ Technologies, Thermo Fisher Scientific, UK), by measuring the absorbance at $260 \mathrm{~nm}$ [43].

PCR was done using genus specific primers, sa- $f$ and $s a-r$ genes of Staphylococcus 16S-1: 5'-GTGCCAGCAGCCGCGGTAA-3' and 5'-AGACCCGGGAACGTATTCAC- $3^{\prime}$. The primers for the $n u c A$ nuclease gene used in our study were $n u c-1$ : $5^{\prime}$-TCAGCAAATGCA TCACAAACAG- $3^{\prime}$ and $n u c-2: 5^{\prime}$-CGTAAATGCACTTGCTTCAGG-3' ${ }^{\prime}$, to highlight the species Staphylococcus aureus. To highlight the mecA gene (gene that confers resistance to methicillin), we used primers: mecA-1: 5'-GGGATCATAGCGTCATTATTC- $3^{\prime}$, respectively $m e c A-2:$ 5'-AACGATTGTGACACGATAGCC-3' [44].

The preparation of the lysosomal digestion buffer was performed by using $200 \mu \mathrm{L}$ of Pure Link ${ }^{\mathrm{TM}}$ Genomic Digestion Buffer (Thermo Fisher Scientific, Basingstoke, UK)/sample, adding fresh lysozyme to obtain a final lysozyme concentration of $20 \mathrm{mg} / \mathrm{mL}$. Up to $2 \times 10$ Gram-negative cells were collected after centrifugation. The cell pellets were re-suspended in $180 \mu \mathrm{L}$ Pure Link ${ }^{\mathrm{TM}}$ Genomic Digestion Buffer and mixed well, then incubated at $37^{\circ} \mathrm{C}$ for half an hour. Twenty $\mu \mathrm{L}$ of proteinase $\mathrm{K}$ were then added and mixed thoroughly. Next, $200 \mu \mathrm{L}$ Pure Link ${ }^{\mathrm{TM}}$ Genomic Lysis/Binding Buffer (Thermo Fisher Scientific, Basingstoke, UK) and mix, then incubate at $55{ }^{\circ} \mathrm{C}$ for $30 \mathrm{~min}$. Next, $200 \mu \mathrm{L}$ of ethanol of $96-100 \%$ concentration was added in the lysate content and mixed thoroughly for $5 \mathrm{~s}$.

The enhanced PCR conditions consisted of an initial denaturation at $95^{\circ} \mathrm{C}$ for $5 \mathrm{~min}$ followed by 32 cycles of denaturation at $95{ }^{\circ} \mathrm{C}$ for $1 \mathrm{~min}$, annealing at $55^{\circ} \mathrm{C}$ for $1 \mathrm{~min}$, 
extension at $72{ }^{\circ} \mathrm{C}$ for $1 \mathrm{~min}$, and a final extension at $72{ }^{\circ} \mathrm{C}$ for $10 \mathrm{~min}$, using the My Cycler (Bio-Rad ${ }^{\circledR}$, Dubai, United Arab Emirates) thermo cycler [45].

Amplicon control was performed by horizontal electrophoresis in the submerged system of $1.5 \%$ agarose gel electrophoresis at $120 \mathrm{~V}$ and $90 \mathrm{~mA}$, over $60 \mathrm{~min}[46,47]$. The amplified products were resolved by electrophoresis on $2.5 \%$ agarose gel, stained with ethidium bromide, and visualized under UV light using a gel documentation system (UV transilluminator-2035-2, Bio Olympics USA).

The strain Staphylococcus aureus ATCC ${ }^{\circledR} 23235^{\mathrm{TM}}$, was used for the positive control (American Type Culture Collection, USA). The control used for the amplification of the $m e c A$ gene in our study was the S. aureus ATCC 49476 (mecA positive), and the $\beta$-lactamase positive S. aureus ATCC 29213 strain was used as a negative control. Sterile deionized water was the negative control for the PCR reactions.

\subsection{Antimicrobials Susceptibility Test}

The Vitek $2^{\circledR}$, AST-GP69 Gram positive specific bacteria card (bioMérieux. Marcy l'Etoile, France), was used to determine antibiotic sensitivities for Staphylococcus isolates collected from shelter dogs, with European Union (EU) drug configuration for companion animals [48].

A total of 19 antimicrobial substances (minimum inhibitory concentration [MIC] from 13 classes were included in the study accordingly: B lactams-benzylpenicillin (PCG; 0.03-0.5 $\mu \mathrm{g} / \mathrm{mL}$ ), oxacillin (OXA; 0.25-4 $\mu \mathrm{g} / \mathrm{mL}$ ), imipenem (IPM; $1-8 \mu \mathrm{g} / \mathrm{mL}$ ), ampicillin (AM; 2-64 $\mu \mathrm{g} / \mathrm{mL}$ ), ampicillin/sulbactam (SAM; 2-64 $\mu \mathrm{g} / \mathrm{mL}$ ); aminoglycosides —gentamicin (GM; $0.5-16 \mu \mathrm{g} / \mathrm{mL})$, kanamycin $(\mathrm{K} ; 0.25-64 \mu \mathrm{g} / \mathrm{mL})$; quinolones-enro floxacin (ENR; 0.25-16 $\mu \mathrm{g} / \mathrm{mL}$ ), marbofloxacin (MBX; 0.25-8 $\mu \mathrm{g} / \mathrm{mL}$ ); steroids-fusidic acid (FUS; 1-16 $\mu \mathrm{g} / \mathrm{mL}$ ); glycopeptides—vancomycin (VAN; 0.25-8 $\mu \mathrm{g} / \mathrm{mL}$ ); macrolides —erythromycin (ERY; 0.25-16 $\mu \mathrm{g} / \mathrm{mL} \mu \mathrm{g} / \mathrm{mL}$ ), rifamycins—rifampicin (RIF; 0.5-8 $\mu \mathrm{g} / \mathrm{mL}$ ); lincomycins-clindamycin (CLI; $0.25-16 \mu \mathrm{g} / \mathrm{mL}$ ), tetracyclines-tetracycline (TE; 2-32 $\mu \mathrm{g} / \mathrm{mL}$ ); sulfonamides-trimethoprim/sulfamethoxazole (SXT; 20-76 $\mu \mathrm{g} / \mathrm{mL}$ ); nitrofuran derivate-nitrofurantoin (FT; 16-512 $\mu \mathrm{g} / \mathrm{mL}$ ); pseudomonic acid derivatives -mupirocin (MUP; 0.06-512 $\mu \mathrm{g} / \mathrm{mL}$ ) and amphenicols-chloramphenicol (CHL; $4-32 \mu \mathrm{g} / \mathrm{mL}$ ). The MIC at which an isolate is considered susceptible according to the Clinical Laboratory Standards Institute (CLSI) guidelines, CLSI M31-A4 2013 [49], based on the description of Humphries et al. [50].

Quality control was performed following the guidelines specified by the CLSI (CLSI, 2008) using Staphylococcus aureus ATCC ${ }^{\circledR} 23235^{\mathrm{TM}}$. All susceptibility results obtained from quality control strains were within the quality control ranges.

This card was used with the Vitek $2^{\circledR}$ Systems in clinical laboratories as an in vitro test to determine clinically significant aerobic Gram-positive bacteria's susceptibility in character with the product information manual.

Isolates resistance to three or more classes of antimicrobials was classified as multidrugresistant [51].

Author Contributions: Conceptualization, D.J. and H.V.; methodology, I.I., P.C., D.R. and D.J.; software, H.V. and D.J. validation, H.V.; formal analysis, D.J. and F.T.; investigation I.I., P.C., H.V., D.R. and D.J.; resources, D.J. and H.V.; data curation, F.T.; writing—original draft preparation, D.J. and H.V.; writing-review and editing, D.J. and H.V.; visualization and supervision, F.T. and H.V.; project administration and funding acquisition, D.J. and H.V. All authors have read and agreed to the published version of the manuscript.

Funding: This paper is published from the own funds of the Banat's University of Agricultural Sciences and Veterinary Medicine from Timisoara and Research Institute for Biosecurity and Bioengineering Timisoara.

Institutional Review Board Statement: The study was conducted according to the guidelines of the Declaration of Helsinki, and approved by the Institutional Review Board (or Ethics Committee) of 
Banat's University of Agricultural Sciences and Veterinary Medicine from Timisoara (protocol code 58/19.05.2019).

Data Availability Statement: The datasets generated and analyzed during the current study are included within the article.

Acknowledgments: The present research was carried out within the Project 7 PCCDI/2018/ Subprogram 1.2-Institutional performance/Complex Projects accomplished in CDI consortia, Romania/2018-2020. One part of this research was supported by COST Action CA18217-European Network for Optimization of Veterinary Antimicrobial Treatment.

Conflicts of Interest: The authors declare no conflict of interest.

\section{References}

1. Kaspar, U.; von Lützau, A.; Schlattmann, A.; Roesler, U.; Köck, R.; Becker, K. Zoonotic multidrug-resistant microorganisms among small companion animals in Germany. PLoS ONE 2018, 13, e0208364. [CrossRef]

2. Constança, P.; Rantala, M.; Greko, C.; Baptiste, K.E.; Boudewijn, C.; van Duijkeren, E.; Mateus, A.; Moreno, M.A.; Pyörälä, S.; Ružauskas, M.; et al. Public health risk of antimicrobial resistance transfer from companion animals. J. Antimicrob. Chemother. 2017, 72, 957-968. [CrossRef]

3. Vincze, S.; Stamm, I.; Monecke, S.; Kopp, P.A.; Semmler, T.; Wieler, L.H.; Lübke-Becker, A.; Walther, B. Molecular analysis of human and canine Staphylococcus aureus strains reveals distinct extended-host-spectrum genotypes independent of their methicillin resistance. Appl. Environ. Microbiol. 2012, 79, 655-662. [CrossRef]

4. Dégi, J. The antimicrobial sensitivity of the coagulase positive staphylococcal strains isolated from otitis externa in dogs, over the period September 2002-May 2003. Bull. Univ. Agric. Sci. Vet. Med. Cluj Napoca 2005, 62, 639.

5. Degi, J.; Imre, K.; Ilie, M.; Cristina, R. Stray dogs as reservoirs of the methicillin-resistant zoonotic stafilococi in an urban area from Romania. J. Biotechnol. 2012, 161, 33. [CrossRef]

6. Cain, C.; Morris, D.; O'Shea, K.; Rankin, S. Genotypic relatedness and phenotypic characterization of Staphylococcus schleiferi subspecies in clinical samples from dogs. Am. J. Vet. Res. 2011, 72, 96-102. [CrossRef]

7. Lozano, C.; Rezusta, A.; Ferrer, I.; Pérez-Laguna, V.; Zarazaga, M.; Ruiz-Ripa, L.; Revillo, M.J.; Torres, C. Staphylococcus pseudintermedius human infection cases in spain: Dog-to-human transmission. Vector Borne Zoonotic Dis. 2017, 17, 268-270. [CrossRef] [PubMed]

8. González-Domínguez, M.S.; Carvajal, H.D.; Calle-Echeverri, D.A.; Chinchilla-Cárdenas, D. Molecular detection and characterization of the mecA and nuc genes from Staphylococcus species (S. aureus, S. pseudintermedius, and S. schleiferi) isolated from dogs suffering superficial pyoderma and their antimicrobial resistance profiles. Front. Vet. Sci. 2020, 7, 376. [CrossRef] [PubMed]

9. Kmieciak, W.; Szewczyk, E.M. Are zoonotic Staphylococcus pseudintermedius strains a growing threat for humans? Folia Microbiol. 2018, 63, 743-747. [CrossRef] [PubMed]

10. Imre, K.; Herman, V.; Morar, A. Scientific achievements in the study of the occurrence and antimicrobial susceptibility profile of major foodborne pathogenic bacteria in foods and food processing environments in Romania: Review of the last decade. BioMed Res. Int. 2020, 2020. [CrossRef]

11. Moses, V.K.; Kandi, V.; Rao, S. Minimum inhibitory concentrations of vancomycin and daptomycin against methicillin-resistant Staphylococcus Aureus isolated from various clinical specimens: A study from south india. Cureus 2020, 12, e6749. [CrossRef]

12. Kanagarajah, R.R.; Lee, D.C.W.; Lee, D.Z.F.; Yusoff, K.; Paramasivam, S.J.; Low, W.Y.; Jeevaratnam, K.; Lim, S.H.E. Antibiotic profiling of methicillin resistant Staphylococcus aureus (MRSA) isolates in stray canines and felines. Cogent Biol. 2017, 3. [CrossRef]

13. Huang, T.M.; Chou, C.C. Methicillin-sensitive and methicillin-resistant Staphylococcus aureus strains and their toxin genes in the nostrils of dogs and workers at an animal shelter. J. Appl. Microbiol. 2019, 126, 1899-1909. [CrossRef]

14. Palma, E.; Tilocca, B.; Roncada, P. Antimicrobial resistance in veterinary medicine: An overview. Int. J. Mol. Sci. 2020, $21,1914$. [CrossRef] [PubMed]

15. Weese, J.S. Methicillin-resistant Staphylococcus aureus in animals. ILAR J. 2010, 51, 233-244. [CrossRef] [PubMed]

16. Loeffler, A.; Boag, A.; Sung, J.M.; Lindsay, J.; Guardabassi, L.; Dalsgaard, A.; Smith, H.; Stevens, K.; Lloyd, D. Prevalence of methicillin-resistant staphylococcus aureus among staff and pets in a small animal referral hospital in the UK. J. Antimicrob. Chemother. 2005, 56, 692-697. [CrossRef] [PubMed]

17. Loeffler, A.; Pfeiffer, D.U.; Lindsay, J.A.; Soares-Magalhaes, R.; Lloyd, D.H. Lack of transmission of methicillin-resistant Staphylococcus aureus (MRSA) between apparently healthy dogs in a rescue kennel. Vet. Microbiol. 2010, 141, 178-181. [CrossRef]

18. Brown, D.F.; Edwards, D.I.; Hawkey, P.M.; Morrison, D.; Ridgway, G.L.; Towner, K.J.; Wren, M.W. Joint working party of the british society for antimicrobial chemotherapy; hospital infection society; infection control nurses association. guidelines for the laboratory diagnosis and susceptibility testing of methicillin-resistant staphylococcus aureus (MRSA). J. Antimicrob. Chemother. 2005, 56, 1000-1018. [CrossRef]

19. Morris, D.O.; Loeffler, A.; Davis, M.F.; Guardabassi, L.; Weese, J.S. Recommendations for approaches to meticillin-resistant staphylococcal infections of small animals: Diagnosis, therapeutic considerations and preventative measures. Clinical consensus guidelines of the world association for veterinary dermatology. Vet. Dermatol. 2017, 28, 304-e69. [CrossRef] 
20. Meroni, G.; Soares Filipe, J.F.; Drago, L.; Martino, P.A. Investigation on antibiotic-resistance, biofilm formation and virulence factors in multi drug resistant and non multi drug resistant Staphylococcus pseudintermedius. Microorganisms 2019, 7, 702. [CrossRef]

21. Little, S.V.; Bryan, L.K.; Hillhouse, A.E.; Cohen, N.D.; Lawhon, S.D. Characterization of agr groups of Staphylococcus pseudintermedius isolates from dogs in texas. mSphere 2019, 27, 4. [CrossRef]

22. Gagetti, P.; Wattam, A.R.; Giacoboni, G.; De Paulis, A.; Bertona, E.; Corso, A.; Rosato, A.E. Identification and molecular epidemiology of methicillin resistant Staphylococcus pseudintermedius strains isolated from canine clinical samples in argentina. BMC Vet. Res. 2019, 15, 264. [CrossRef]

23. Grönthal, T.; Eklund, M.; Thomson, K.; Piiparinen, H.; Sironen, T.; Rantala, M. Antimicrobial resistance in Staphylococcus pseudintermedius and the molecular epidemiology of methicillin-resistant S. pseudintermedius in small animals in Finland. J. Antimicrob. Chemother. 2017, 4, 1021-1030. [CrossRef] [PubMed]

24. Haenni, M.; El Garch, F.; Miossec, C.; Madec, J.Y.; Hocquet, D.; Valot, B. High genetic diversity among methicillin-susceptible Staphylococcus pseudintermedius in dogs in Europe. J. Glob. Antimicrob. Resist. 2020, 21, 57-59. [CrossRef] [PubMed]

25. Smith, J.T.; Amador, S.; McGonagle, C.J.; Needle, D.; Gibson, R.; Andam, C.P. Population genomics of Staphylococcus pseudintermedius in companion animals in the United States. Commun. Biol. 2020, 3, 282. [CrossRef]

26. Dalton, K.R.; Rock, C.; Carroll, K.C.; Davis, M.F. One health in hospitals: How understanding the dynamics of people, animals, and the hospital built-environment can be used to better inform interventions for antimicrobial-resistant gram-positive infections. Antimicrob. Resist. Infect. Control. 2020, 9, 78. [CrossRef] [PubMed]

27. Kranjec, C.; Morales Angeles, D.; Torrissen Mårli, M.; Fernández, L.; García, P.; Kjos, M.; Diep, D.B. Staphylococcal biofilms: Challenges and novel therapeutic perspectives. Antibiotics 2021, 10, 131. [CrossRef]

28. Bhooshan, S.; Negi, V.; Khatri, P.K. Staphylococcus pseudintermedius: An undocumented, emerging pathogen in humans. GMS Hyg. Infect. Control 2020, 15, 32. [CrossRef]

29. Boost, M.V.; O’Donoghue, M.M.; James, A. Prevalence of Staphylococcus aureus carriage among dogs and their owners. Epidemiol. Infect. 2008, 136, 953-964. [CrossRef]

30. Jung, W.K.; Shin, S.; Park, Y.K.; Noh, S.M.; Shin, S.R.; Yoo, H.S.; Park, S.C.; Park, Y.H.; Park, K.T. Distribution and antimicrobial resistance profiles of bacterial species in stray dogs, hospital-admitted dogs, and veterinary staff in South Korea. BMC Vet. Res. 2020, 184. [CrossRef]

31. Mackenzie, J.S.; Jeggo, M. The one health approach-why is it so important? Trop. Med. Infect. Dis. 2019, 4, 88. [CrossRef] [PubMed]

32. McEwen, S.A.; Collignon, P.J. Antimicrobial resistance: A one health perspective. Microbiol. Spectr. 2018, 6. [CrossRef] [PubMed]

33. Collignon, P.J.; McEwen, S.A. One health-its importance in helping to better control antimicrobial resistance. Trop. Med. Infect. Dis. 2019, 4, 22. [CrossRef] [PubMed]

34. Gingrich, E.N.; Kurt, T.; Hyatt, D.R.; Lappin, M.R.; Ruch-Gallie, R. Prevalence of methicillin-resistant staphylococci in northern Colorado shelter animals. J. Vet. Diagn. Investig. 2011, 23, 947-950. [CrossRef]

35. Hanselman, B.A.; Anderson, M.; Kruth, S. Prevalence of methicillin-resistant Staphylococcus aureus colonization in dogs entering a veterinary teaching hospital. J. Vet. Intern. Med. 2005, 19, 464.

36. Abbott, Y.; Leggett, B. Rossney, Isolation rates of methicillin-resistant Staphylococcus aureus in dogs, cats, and horses in Ireland. Vet. Rec. 2010, 166, 451-455. [CrossRef]

37. Biosafety Manual of the University Veterinary Clinics of Timisoara. 2019. Available online: https://www.usab-tm.ro/utilizatori/ medicinaveterinara/file/Manual\%20Biosecuritate\%20CVU\%202019.pdf (accessed on 18 February 2021).

38. Miller, L. Dog and cat care in the animal shelter. In Shelter Medicine for Veterinarians and Staff; Miller, L., Zawistowski, S., Eds.; Blackwell: Ames, IA, USA, 2004; pp. 95-123.

39. Buommino, E.; Vollaro, A.; Nocera, F.P.; Lembo, F.; DellaGreca, M.; De Martino, L.; Catania, M.R. Synergistic effect of abietic acid with oxacillin against methicillin-resistant Staphylococcus pseudintermedius. Antibiotics 2021, 10, 80. [CrossRef]

40. Bellavita, R.; Vollaro, A.; Catania, M.R.; Merlino, F.; De Martino, L.; Nocera, F.P.; DellaGreca, M.; Lembo, F.; Grieco, P.; Buommino, E. Novel antimicrobial peptide from Temporin L in the treatment of Staphylococcus pseudintermedius and Malassezia pachydermatis in polymicrobial inter-kingdom infection. Antibiotics 2020, 9, 530. [CrossRef]

41. Funke, G.; Funke-Kissling, P. Performance of the new VITEK 2 GP card for identification of medically relevant gram-positive cocci in a routine clinical laboratory. J. Clin. Microbiol. 2005, 43, 84-88. [CrossRef]

42. Nilsson, P.; Alexandersson, H.; Ripa, T. Use of broth enrichment and real-time PCR to exclude the presence of methicillin-resistant Staphylococcus aureus in clinical samples: A sensitive screening approach. Clin. Microbiol. Infect. 2005, 11, 1027-1034. [CrossRef]

43. Vingataramin, L.; Frost, E.H. A single protocol for extraction of gDNA from bacteria and yeast. Biotechniques 2015, 58, 120-125. [CrossRef] [PubMed]

44. Poulsen, A.B.; Skov, R.; Pallesen, L.V. Detection of methicillin resistance in coagulase-negative staphylococci and in staphylococci directly from simulated blood cultures using the EVIGENE MRSA detection kit. J. Antimicrob. Chemother. 2003, 51, 419-421. [CrossRef]

45. Adwan, K. Fast DNA isolation and PCR protocols for detection of methicillin-resistant staphylococci. Folia Microbiol. 2014, 59, 5-8. [CrossRef] [PubMed]

46. Lee, P.Y.; Costumbrado, J.; Hsu, C.Y.; Kim, Y.H. Agarose gel electrophoresis for the separation of DNA fragments. J. Vis. Exp. 2012, 20, 62-3923. [CrossRef] [PubMed] 
47. Rantakokko-Jalava, K.; Jalava, J. Optimal DNA isolation method for detection of bacteria in clinical specimens by broad-range PCR. J. Clin. Microbiol. 2002, 40, 4211-4217. [CrossRef]

48. The European Committee on Antimicrobial Susceptibility Testing. Breakpoint Tables for Interpretation of MICs and Zone Diameters. Version 8.0. 2008. Available online: http://www.eucast.org/fileadmin/src/media/PDFs/EUCAST_files/Breakpoint_ tables/v_8.0_Breakpoint_Tables.pdf (accessed on 18 February 2021).

49. Clinical Laboratory Standards Institute. Performance Standards for Antimicrobial Disk and Dilution Susceptibility Tests for Bacteria Isolated from Animals; Approved Standard, 4th ed.; CLSI M31-A4/VET01-A4; Clinical Laboratory Standards Institute: Wayne, PA, USA, 2013; Volume 33.

50. Humphries, R.M.; Abbott, A.N.; Hindler, J.A. Understanding and addressing CLSI breakpoint revisions: A primer for clinical laboratories. J. Clin. Microbiol. 2019, 57. [CrossRef]

51. Sweeney, M.T.; Lubbers, B.V.; Schwarz, S.; Watts, J.L. Applying definitions for multidrug resistance, extensive drug resistance and pandrug resistance to clinically significant livestock and companion animal bacterial pathogens. J. Antimicrob. Chemother. 2018, 73, 1460-1463. [CrossRef] [PubMed] 